\title{
Microbial diversity in innovative mesophilic/thermophilic temperature-phased anaerobic digestion of sludge
}

\author{
M. C. Gagliano • C. M. Braguglia • A. Gallipoli • \\ A. Gianico $\cdot$ S. Rossetti
}

Received: 7 March 2014 / Accepted: 19 May 2014

(C) Springer-Verlag Berlin Heidelberg 2014

\begin{abstract}
Anaerobic digestion (AD) is one of the few sustainable technologies that both produce energy and treat waste streams. Driven by a complex and diverse community of microbes, AD may be affected by different factors, many of which also influence the composition and activity of the microbial community. In this study, the biodiversity of microbial populations in innovative mesophilic/thermophilic temperature-phased $\mathrm{AD}$ of sludge was evaluated by means of fluorescence in situ hybridization (FISH). The increase of digestion temperature drastically affected the microbial composition and selected specialized biomass. Hydrogenotrophic Methanobacteriales and the protein fermentative bacterium Coprothermobacter spp. were identified in the thermophilic anaerobic biomass. Shannon-Weaver diversity $\left(H^{\prime}\right)$ and evenness $(E)$ indices were calculated using FISH data. Species richness was lower under thermophilic conditions compared with the values estimated in mesophilic samples, and it was flanked by similar trend of the evenness indicating that thermophilic communities may be therefore more susceptible to sudden changes and less prompt to adapting to operative variations.
\end{abstract}

Keywords Methanogenic archaea - Syntrophic association . Ultrasounds pretreatment · Anaerobic digestion · Mesophilic/ thermophilic dual stage $\cdot$ Waste-activated sludge $\cdot$ Microbial diversity $\cdot$ Fluorescence in situ hybridization

Responsible editor: Robert Duran

M. C. Gagliano • C. M. Braguglia • A. Gallipoli • A. Gianico • S. Rossetti $(\bowtie)$

Water Research Institute, IRSA-CNR, Via Salaria km 29,300, Monterotondo, RM 00015, Italy

e-mail: rossetti@irsa.cnr.it

\section{Introduction}

Anaerobic digestion (AD) is a robust and efficient technology for the energetic valorization of various types of biomass (including organic wastes and sewage sludge), and it is expected to play a crucial role in the future of renewable energy production (Lauwers et al. 2013). AD of organic matter occurs through the sequential cooperation of different microbial groups in order to achieve degradation of a variety of polymeric and monomeric substrates (O'Flaherty et al. 2006). The anaerobic degradation of organic matter proceeds in a series of four metabolic steps: hydrolysis, acidogenesis, acetogenesis, and methanogenesis. A diverse number of bacteria take part in the first three steps, and methane formation is mainly derived from acetate and hydrogen $/ \mathrm{CO}_{2}$ conversion by methanogenic archaea. A balanced interaction between the microorganisms in this chain is crucial for an efficient biogas production. Thus, a better understanding of the structure and function of microbial communities during $\mathrm{AD}$ may help to improve the reactor performances. However, organic particulate matter degradation efficiency of $\mathrm{AD}$ of waste-activated sludge (WAS) remains limited, because of the hydrolysis, considered the ratelimiting step of the entire process (Pavlostathis and GiraldoGomez 1991; Bougrier et al. 2006). In order to increase or accelerate the biodegradation rates, various pretreatments (thermal, enzymatic, chemical, or mechanical) have been widely investigated (Carrère et al. 2010; Carlsson et al. 2012). Ultrasounds are currently applied as pretreatment also at full scale on sewage treatment plants. The action of the ultrasonic treatment is to disrupt mechanically the sludge floc matrix and the cell structure by means of shear forces due to cavitation phenomena. Moreover, phased AD in which two or more digesters are used in series is a promising technology for the treatment of wastewater sludges (Zamanzadeh et al. 2013). In the last years, a temperature-phased anaerobic process (TPAD) with a short thermophilic stage acting as thermal 
pretreatment, followed by a longer mesophilic one was investigated with the aim to separate microbial groups into two phases (Coelho et al. 2011; Ge et al. 2010). In the first thermophilic with short hydraulic retention time, hydrolytic and acidogenic/fermentative bacteria degrade polymers to monomers and produce organic acids. In the second stage (with a much longer retention time), these products are then converted into methane by strict cooperation between bacteria and archaea during acetogenesis and methanogenesis (Merlino et al. 2013). However, detailed knowledge of the microbial community structure and their function is lacking (Pervin et al. 2013a).TPAD is particularly applicable to AD of activated sludge, as it allows increased performance regarding solids removal and methane production at a moderate energy input and moderate pathogen removal (Paul et al. 2012). Studies of these microbial communities are limited, and knowledge of the ecology and how that may be related to the system operation is just beginning to develop (Pervin et al. 2013b). Nevertheless, the microbial population is likely to be competent in anaerobic hydrolytic and acidogenic functions, and hence likely to be bacterial rather than archaeal or eukaryotic (Amani et al. 2010). The new approach of this study was based on the idea to subdivide the $\mathrm{AD}$ process into three different stages: (1) an ultrasounds pretreatment to improve hydrolysis, (2) a short mesophilic stage to improve volatile fatty acids (VFA) formation, and (3) a final thermophilic stage to convert these intermediates into methane and contemporarily assure the complete hygienization of the digested sludge. Focus of this study was the characterization of the microbial communities growing in this innovative system, fed by real WAS, either untreated or ultrasounds pretreated. The study was specifically aimed at understanding the microbial composition of the mesophilic and thermophilic anaerobic biomass under different conditions of temperature, organic loading rate, and substrate solubilization and availability. Investigation was performed by fluorescence in situ hybridization (FISH) using a wide range of oligonucleotide probes with broad and narrow specificity.

\section{Material and methods}

\section{Sludge}

WAS samples were obtained from the municipal "RomaNord" wastewater treatment plant, characterized by an organic load of about 700,000 p.e., high sludge age (20 days) and a chemical oxygen demand (COD) average value of incoming sewage of $200 \mathrm{mg} / \mathrm{L}$. The activated sludge was sampled directly from the oxidation tank. The anaerobic inoculum utilized for the startup of the mesophilic stage was sampled from the full-scale digester of the plant-treating mixed sludge, while the anaerobic biomass for the thermophilic reactors originated from a previous experimentation with semicontinuous thermophilic system (Gianico et al. 2013).

\section{Sludge pretreatment}

The disintegration by ultrasound was performed with an ultrasonic processor UP400S (dr. Hielscher, Germany) operating at $300 \mathrm{~W}$ and $24 \mathrm{kHz}$. Sonication energy input was set at $0.4-0.5 \mathrm{kWh} \mathrm{kg}^{-1}$ dry solid on $500 \mathrm{~mL}$ of WAS $(2.9-4.7 \%$ total solid (TS)) placed in $1 \mathrm{~L}$ beaker with the probe allocated at $3 \mathrm{~cm}$ above the beaker bottom.

\section{Mesophilic/thermophilic dual-stage AD}

Sludge digestion was carried out using four anaerobic digesters operated in semicontinuous mode. Two reactors, as control line, were used to carry out the mesophilic/ thermophilic digestion of untreated WAS; the other two reactors, as experimental line, were selected to treat the same sludge, but after sonication (Fig. 1). All jacketed reactors $(V=7 \mathrm{~L})$ were completely mixed: the first mesophilic digester was maintained at the constant temperature of $37^{\circ} \mathrm{C}$, while the thermophilic reactor was maintained at $55^{\circ} \mathrm{C}$. In the first test, the organic loading rate (OLR) to the first mesophilic reactor was fixed at $3.9 \mathrm{~kg}$ volatile solid (VS) $\mathrm{m}^{-3}$ day $^{-1}$ and to the successive thermophilic at $1.2 \mathrm{~kg} \mathrm{VS} \mathrm{m}^{-3} \mathrm{day}^{-1}$; in the second test, the OLR was increased up to 10 for the mesophilic and $2.5 \mathrm{~kg} \mathrm{VS} \mathrm{m}^{-3}$ day $^{-1}$ for the thermophilic reactor, by decreasing the hydraulic retention time (HRT) in the mesophilic reactor and by prethickening the incoming feed sludge. Table 2 lists the operating conditions of the $\mathrm{AD}$ tests.

\section{Biogas collection and analysis}

The produced biogas was collected by water displacement in a biogas collection unit. The gas meter consisted of a volumetric cell for gas-liquid displacement, a sensor device for liquid level detection, and an electronic control circuit for data processing and display. The methane content in the biogas was measured using a PerkinElmer Auto System Gas Chromatographer equipped with a thermal conductivity detector (TCD) as described in Gianico et al. (2013).

\section{Matter composition}

TS and VS were determined in triplicates according to standard methods (APHA 1998). The $\mathrm{pH}$ was measured by a portable $\mathrm{pH}$ meter (WTW, $\mathrm{pH}$ 330/SET-1). To analyze sludge organic content, the particulate sludge matter was removed by centrifugation (10 min at 5,000 rpm), and the resulting concentrate was filtrated through $0.2,0.45$, and $1.2 \mu \mathrm{m}$ pore size membrane filters. 
Fig. 1 Schematic diagram of the mesophilic/thermophilic process on untreated (a) and sonicated (b) WAS

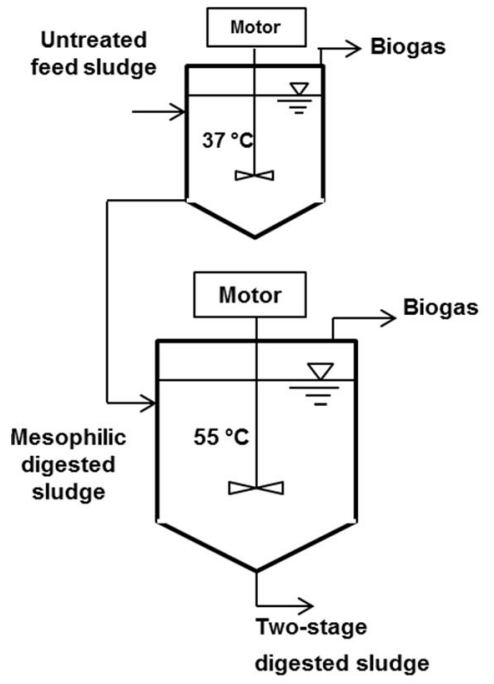

(a)

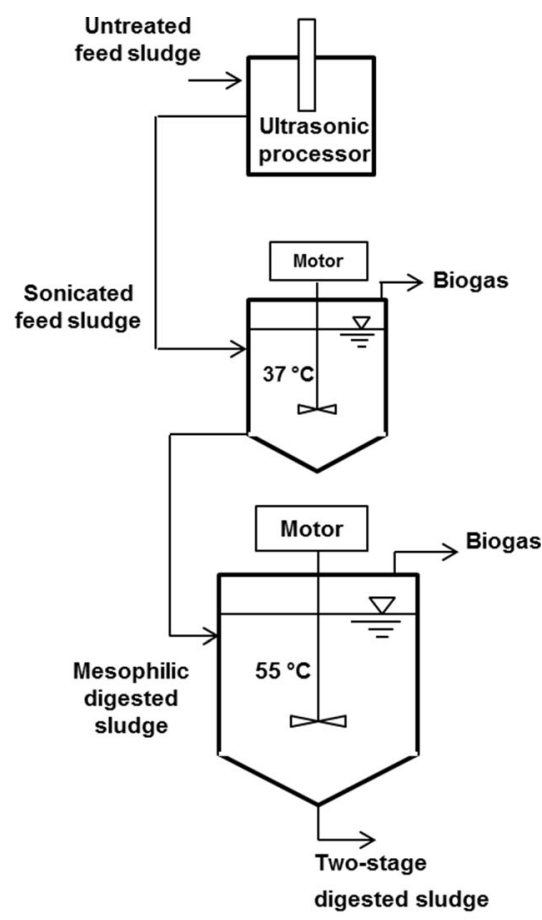

(b)
VFA were quantified from $0.2 \mu \mathrm{m}$ filtrate (soluble phase) by gas chromatography using PerkinElmer Auto System Gas Chromatographer with flame ionization detector (FID). The GC analyses were performed on a stainless steel column packed with 60/80 mesh Carboxen C, $0.3 \%$ Carbowax (Supelco, USA), under the following conditions: injector, $200{ }^{\circ} \mathrm{C}$; oven, $175^{\circ} \mathrm{C}$; and detector, $250{ }^{\circ} \mathrm{C}$. Nitrogen was used as a carrier gas at a flow rate of $30 \mathrm{~mL} / \mathrm{min}$. Soluble COD (sCOD), was determined on $0.45 \mu \mathrm{m}$ filtrate (soluble phase) by Cell Test Spectroquant (Merck) as described in Gianico et al. (2013). Protein content was determined on $1.2 \mu \mathrm{m}$ filtrate (colloidal phase) by BCA colorimetric method as described in Braguglia et al. (2012).

Microbial community analysis

\section{Sample collection}

Effluent sludge samples were collected from reactors during the steady-state operation of the systems. These samples were fixed with paraformaldehyde and ethanol for FISH analysis as described in Amann and Binder (1990).

\section{Fluorescence in situ hybridization}

FISH on fixed sludge samples was performed as previously described (Braguglia et al. 2012). Details of the employed oligonucleotide probes are available at probeBase (Loy et al.
2007). Probes were labelled with Cy3 or FITC fluorophores. To identify thermophilic archaea of the order Methanobacteriales, the protocol was modified as described in Nakamura et al. (2006), by applying the enzyme pseudomurein endopeptidase (rPeiW) to improve probe penetration inside cells. The lyophilized $\mathrm{rPeiW}$ was provided from Dr. Kohei Nakamura (Laboratory of Environmental Microbiology and Engineering, Faculty of Applied and Life Sciences, Gifu University).

\section{Microscopy and fluorescence signal quantification}

Samples were examined by epifluorescence microscopy (Olympus BX51) using filters for FITC (excitation, 470$490 \mathrm{~nm}$; emission, $520 \mathrm{~nm}$ ) and for CY3 (exCitation, $546 \mathrm{~nm}$; emission, $590 \mathrm{~nm}$ ). Autofluorescence was tested by performing a control test on unstained samples observed with both filters used for FISH analysis. No autofluorescence was retrieved in all screened samples. Fluorescence signal was quantified on microscopic images taken from the samples with a digital camera (Olympus XM-10) and the software Cell F. All the hybridizations with specific probes were carried out in combination with DAPI staining to estimate the portion of cells targeted by group specific probes out of the total cells. Area measurements of the hybridised cells were reported as a portion of the area covered by total DAPI stained cells in each field. Area measurements were performed on at least ten JPEG images (or other image format with 8 bit size of $1,388 \times$ 
1,040 pixels) using ImageJ software package (version1.37v, Wayne Rasband, National Institute of Health, Bethesda, MD, USA, available in the public domain at http://rsb.info.nih.gov/ ij/index.html) as described in Braguglia et al. (2012).

\section{Microbial diversity}

The relative abundance of each microbial component calculated by FISH out of total cells (estimated by DAPI staining) was utilized to calculate the biodiversity of the mixed microbial communities by means of Shannon-Weaver index of diversity $\left(H^{\prime}\right)$ (Shannon and Weaver 1963) and Pielou's evenness index (Heip 1974).

\section{Results and discussion}

Reactor performances and microbial population dynamics

The innovative process described here is based on the integration of a mechanical pretreatment before a dual-stage mesophilic-thermophilic digestion process (Gianico et al. 2014). The scope of this layout was to improve the hydrolysis and the fermentation steps during the mesophilic digestion of sonicated sludge, while the successive long thermophilic stage could additionally improve organic matter biodegradation obtaining higher methane yield and sludge hygenization. The composition and the structure of the anaerobic biomass selected during both mesophilic and thermophilic stages were investigated to better understand the effect of the operating conditions on microbial community in order to achieve better process performances.

\section{Mesophilic microbial community}

As shown in Fig. 2, the bacterial population identified by FISH ranged between 55 and $65 \%$ of total DAPI-stained cells and was mainly composed of Proteobacteria, commonly found as main components of activated sludge (Wilén et al. 2008). Changes in HRT did not affect the amount of bacteria retrieved in the anaerobic biomass in the reactor fed with ultrasound-pretreated sludge (Fig. 2b), despite the higher organic loading rate (Table 1). Overall, in the reactor fed with ultrasound-pretreated sludge, the impact of operative changes was negligible with respect to the control reactor, although slight variations in the relative abundance of individual components were observed. The relative abundance of archaeal population decreased with the increase of OLR in both sonicated and untreated biomass. (Fig. 2).This is in agreement with the biogas production of the mesophilic reactors that was higher in test 1 with respect to test 2 (Fig. 3). Shortening the HRT of the first mesophilic stage reduced the extent of conversion of substrates in methane, benefiting the biogas production of following thermophilic stage in test 2 (Fig. 3). The latter was confirmed by VFA measurements in mesophilic samples during the two tests (Fig. 4). In test 1 (Fig. 4a, b), only acetate and propionate were detected, but the concentration was very low $(<30 \mathrm{mg} / \mathrm{L})$. Diversely, during test 2 , VFA were found at higher concentrations, ranging from 0.5 to $1 \mathrm{~g} / \mathrm{L}$ in the control reactor and from 0.7 to about $2.5 \mathrm{~g} / \mathrm{L}$ in the reactor fed with sonicated sludge (Fig. 4c, d). Additionally, VFA were present also in the form of butyrate and isobutyrate. These VFA, conveyed as feed into the thermophilic reactor, enhanced consequently the biogas yield with respect to test 1 . This indicated that in the mesophilic stage of test 1 the conversion rate of organic substrates into methane was higher than in test 2 , with a consequent loss of the methanogenic potential incoming in the thermophilic reactor. Indeed, in test 1 the mesophilic stage produced the majority of the total biogas during the two-stage digestion (Fig. 3). Shortening the HRT and increasing the OLR of the mesophilic reactor led to the improvement of the performance of the following thermophilic stage in test 2 , encountering the original aim of the mesophilic stage. The application of specific FISH probes for archaea showed the presence of long filamentous and rods of Methanosaeta spp. The latter was found in all digestion phases, highlighting the occurrence of acetotrophic methanogenesis as expected in a mesophilic anaerobic system. The occurrence of these microorganisms is strictly related to acetate concentration, because Methanosaeta is a specialist in using acetate and grows only at low acetate concentrations. Fluctuations in relative abundance (Fig. 5) of this microorganism during the two tests (a decrease during test 1 and an increase during test 2 in both reactors) are mainly due to rapid changes in acetate concentration (which constitutes the largest portion of VFA present in the system) observed during the fermentative step of $\mathrm{AD}$, as shown in Fig. 4. The remaining part of archaeal population was not identified by applying the available FISH probes.

\section{Thermophilic microbial community}

As shown in Fig. 6, proteolitic fermentative bacteria Coprothermobacter and hydrogenotrophic Methanobacteriales were found as component in the microbial community. Microbial composition of the inoculum is reported in Fig. 6a. Methanobacteriales cells were further identified as Methanothermobacter sp. by generating an archaeal 16S rRNA gene clone library from total community DNA isolated from sludge samples (data not shown). The latter finding is in line with many previous studies where Coprothermobacter and Methanothermobacter were found to live in strict syntrophic associations (Sasaki et al. 2011; Ge et al. 2012). Proteolytic activity of Coprothermobacter is well documented (Etchebehere et al. 1998; Tandishabo et al. 2012; Majeed 
Fig. 2 Relative abundance of bacteria and archaea, out of total cells in mesophilic reactors fed with untreated (a) and sonicated (b) sludge operating at steadystate conditions. FISH oligonucleotide probes applied for the analysis are reported in brackets
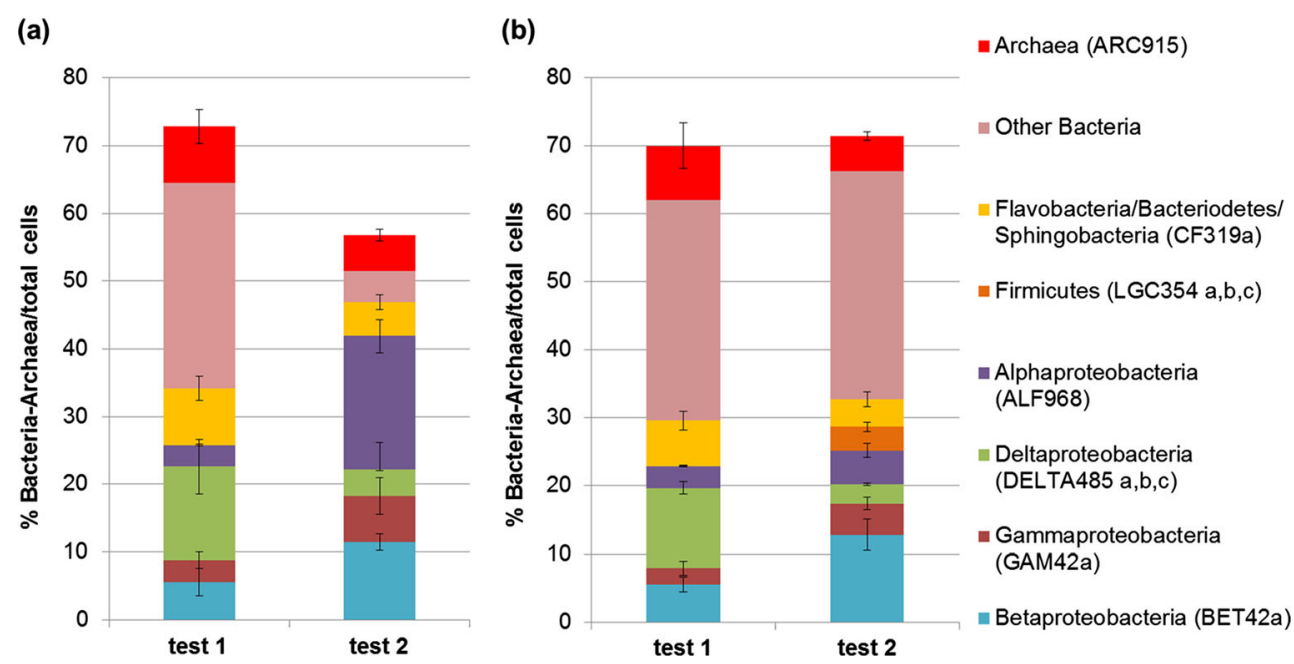

et al. 2013; Lü et al. 2014), and in particular this microorganism is capable to ferment proteins, growing well in presence of peptides (Ollivier et al. 1985). Therefore, the solubilization of proteins into small molecules can promote Coprothermobacter establishment, especially at high temperatures (Lee et al. 2009). In this mesophilic/thermophilic digestion system, Coprothermobacter decreased with increased OLR indicating a failure in acclimation under the new reactor conditions (Fig. 6). Sasaki et al. (2011) reported that the growth of Coprothermobacter was proportional to protein consumption. Tandishabo et al. (2012) highlighted that Coprothermobacter population size was controlled by the type of substrates in the feed. Evidently, fermentative pathways were different with respect to the original thermophilic reactor from which the inoculum was sampled. In particular, sonication pretreatment and/or mesophilic stage generated substrates in which proteic components were not degraded into small molecules. Sonication pretreatment generally seems to affect Coprothermobacter relative abundance in test 1 (Fig. 6b, c), with the increase of other bacteria in the system fed with sonicated sludge (Fig. 6c). In test 1 , after sonication and mesophilic stage, proteins concentration was about $260 \mathrm{mg} / \mathrm{L}$ and the sCOD value increased up to $250 \mathrm{mg} / \mathrm{L}$ (Table 2). Regarding the second test, the OLR increase of the mesophilic stage highly improved SCOD and proteins release and accumulation in the reactor, but this had no

Table 1 Operating conditions of mesophilic ( $1^{\circ}$ stage $)$ and thermophilic $\left(2^{\circ}\right.$ stage $)$ digestion tests

\begin{tabular}{|c|c|c|c|c|}
\hline & \multicolumn{2}{|l|}{ Test 1} & \multicolumn{2}{|l|}{ Test 2} \\
\hline & $1^{\circ}$ stage & $2^{\circ}$ stage & $1^{\circ}$ stage & $2^{\circ}$ stage \\
\hline$T\left({ }^{\circ} \mathrm{C}\right)$ & $37^{\circ} \mathrm{C}$ & $55^{\circ} \mathrm{C}$ & $37^{\circ} \mathrm{C}$ & $55^{\circ} \mathrm{C}$ \\
\hline OLR (g VS L ${ }^{-1}$ day $^{-1}$ ) & 3.9 & 1.2 & 10 & 2.5 \\
\hline HRT (day) & 5 & 10 & 3 & 10 \\
\hline Test duration (day) & 97 & 97 & 81 & 81 \\
\hline
\end{tabular}

positive effect on the maintenance of Coprothermobacter population in the thermophilic reactor. Indeed, as described in Bougrier et al. (2005), after low-frequency ultrasounds pretreatment, proteins were made soluble but not completely degraded, as very little organic nitrogen was transformed into ammonium.

An additional factor influencing Coprothermobacter population was likely the HRT of the mesophilic stage: the shortening of HRT from tests 1 to 2 may have decreased the proportion of protein degradation during mesophilic hydrolysis. The percentage of acetate degradation in thermophilic

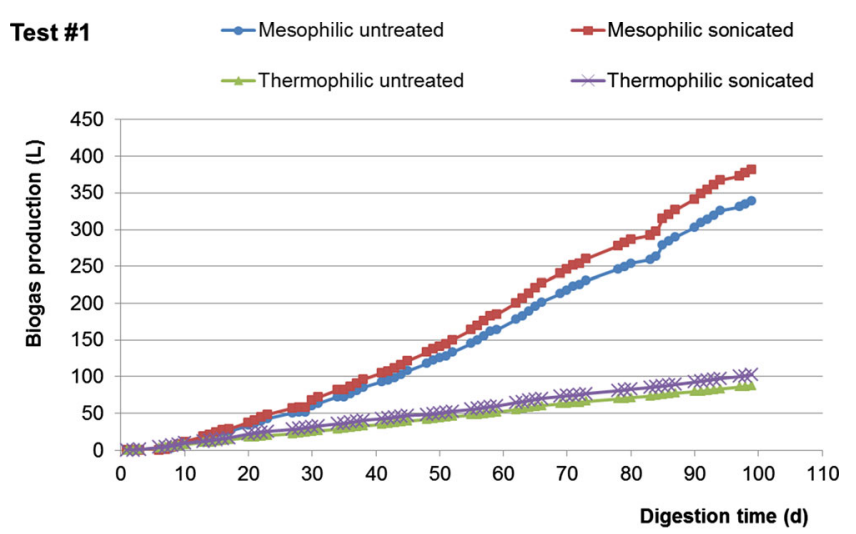

Test \#2

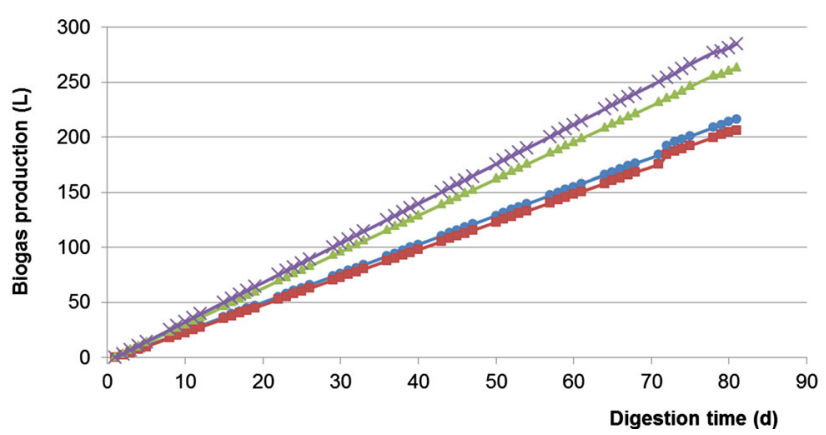

Fig. 3 Mesophilic and thermophilic cumulative biogas production during the anaerobic tests 
Fig. 4 VFA trends in mesophilic reactors fed with untreated $(\mathbf{a}, \mathbf{c})$ and sonicated $(\mathbf{b}, \mathbf{d})$ sludge during tests 1 (a and $\mathbf{b})$ and 2 (c and $\mathbf{d}$ ) (a)
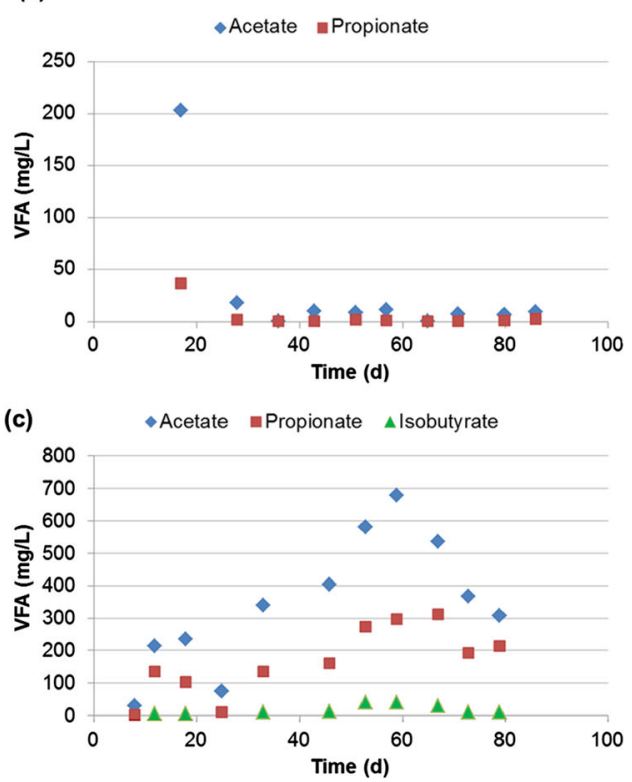

(b)
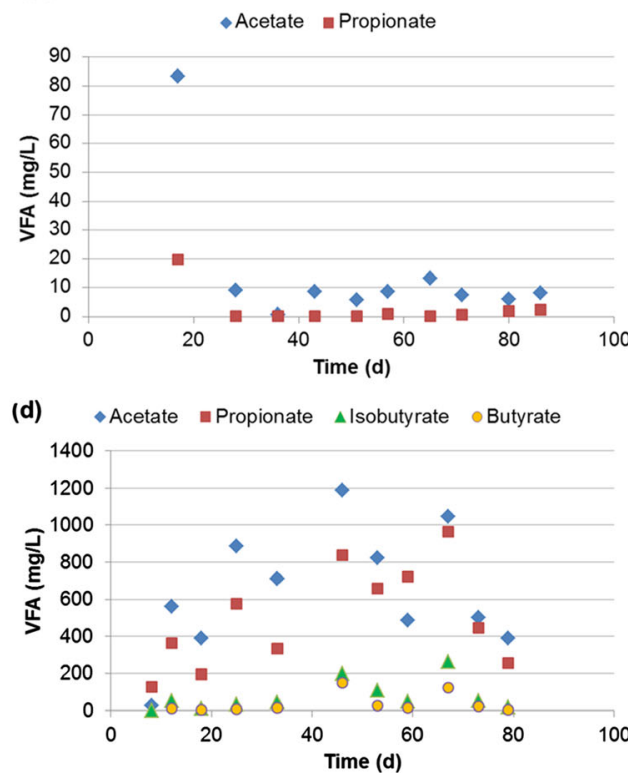

reactors during test 2 , with respect to the incoming sludge from mesophilic reactors is shown in Fig. 7. Acetate degradation occurred in both reactors, but was higher in the reactor fed with sonicated sludge. Thus, the high concentration of VFA transferred from mesophilic to thermophilic stage in test 2, definitely changed the pathway of methanogenesis. All these observations can easily explain the decrease in relative abundance of Coprothermobacter in the end-stage compared with the startup population. Conversely, Methanothermobacter was the only methanogen retrieved in the anaerobic sludge (Fig. 6). This was mainly due to the VFA accumulation from mesophilic stage, because Methanothermobacter is less sensitive than acetoclastic methanogens to increases in VFA concentration (Hori et al. 2006). This means that hydrogenotrophic methanogenesis was the main way of methane production, but the hydrogen production pathway was not driven by Coprothermobacter population, and likely other kind of syntrophic associations take place. The hydrogen supply seemed to be the key parameter affecting biogas production, rather than the population size of Methanothermobacter, as described in Morgan et al. (1997). The lack of aceticlastic methanogens indicated that acetate was neither cleaved nor oxidized by archaea, and therefore, under these conditions, at high acetate concentration, the most probable way of methane production is the syntrophic oxidation of acetate (SAO) to hydrogen by syntrophic acetateoxidizing bacteria (not identified in this study), followed by hydrogen removal by Methanothermobacter (Karakashev et al. 2006; Ge et al. 2012). SAO is a key pathway at elevated temperatures (Ho et al. 2013). However, some studies have recently found that $\mathrm{SAO}$ became predominant in thermophilic or stressed environmental conditions (Hao et al. 2011), but microorganisms involved in this pathway are widely under investigations. As reported by Lü et al. (2014), Coprothermobacter may also operate SAO with consequent production of hydrogen, but cooperation with several bacterial species is required. Thus, population composition of startup thermophilic biomass progressively changed, but strong
Fig. 5 Relative abundance of archaea (ARC915 probe) and Methanosaeta (MX825a,b,c probes) out of total cells in mesophilic reactors fed with untreated (a) and sonicated (b) sludge for the two digestion tests, at the beginning and at the end of each digestion test

$\square$ Methanosaeta $\square$ other Archaea

(A)

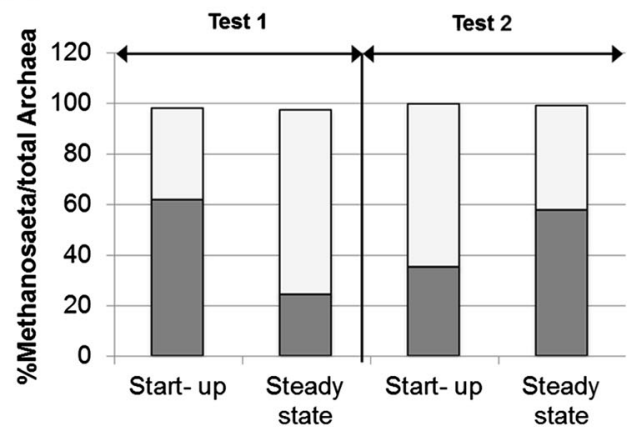

(B)

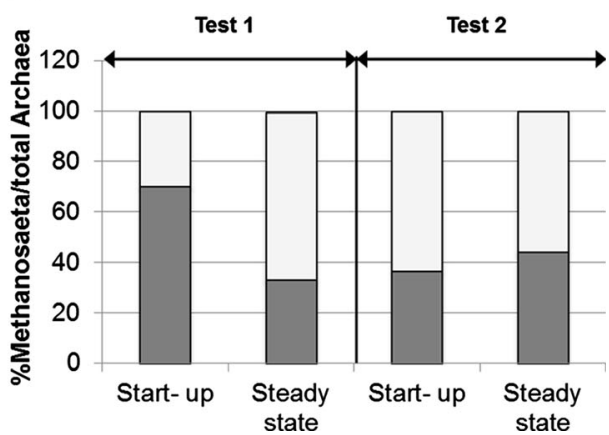


(a)

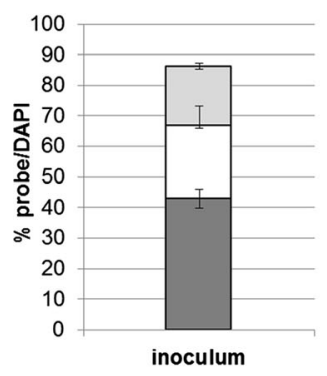

(b)

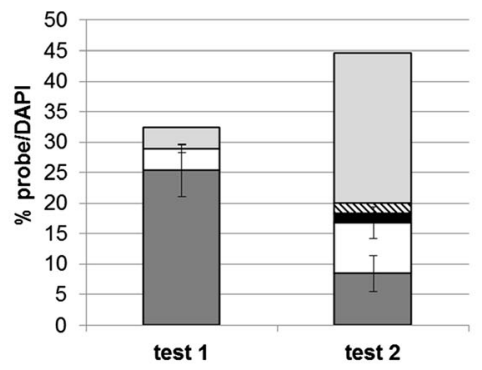

(c)

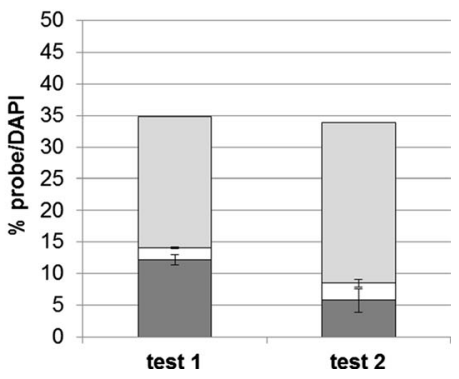

Fig. 6 Relative abundance of bacteria (EUB338mix probes), Coprothermobacter (CTH485 probe), Betaproteobacteria (BETA42A probe), Firmicutes (LGC354a,b,c), and Methanobacteriales (MB311 probe) out of total cells in thermophilic reactors fed with untreated (b) and sonicated (c) sludge for the two digestion tests, at the end of each digestion period. In (a), the microbial composition of thermophilic inoculum is reported

strong impact of microbial biodiversity on the process evolvement was highlighted in the previous sections: during mesophilic stage, microbial population quickly changed in response to variations in HRT and OLR, switching from methane to VFA production (Figs. 3 and 4), with negligible variations of microbial composition and relative abundance. Conversely, during thermophilic stage, the startup microbial population slowly evolved encountering operative variations, changing the way of fermentative hydrogen production.

Differences between mesophilic and thermophilic microbial communities in anaerobic digesters are largely reported (Ike et al. 2010; Shi et al. 2013; Pervin et al. 2013a; Zamanzadeh et al. 2013). A systematical analysis of 21 mesophilic and thermophilic full-scale anaerobic digesters highlighted that bacterial and archaeal community composition was mainly related to the temperature of the process (Sundberg et al. 2013). Looking at the distribution of microbial population within archaea and bacteria domains, in the study of Nelson et al. (2011) a meta analysis of microbial diversity in several $\mathrm{AD}$ systems revealed that species richness of bacteria is higher than archaea. Generally, in studies based on in situ identification, archaeal relative abundance is lower than bacterial one (Ariesyady et al. 2007; Montero et al. 2009; Krakat et al. 2010). Indeed, hydrolytic and fermentative steps require the cooperation of different bacterial groups that degrade the wide range of
Table 2 Soluble COD and proteins during steady state of dualdigestion tests 1 and 2

\begin{tabular}{|c|c|c|c|c|c|c|}
\hline & \multicolumn{3}{|l|}{ Untreated } & \multicolumn{3}{|l|}{ Sonicated } \\
\hline & Feed & $1^{\circ}$ stage & $2^{\circ}$ stage & Feed & $1^{\circ}$ stage & $2^{\circ}$ stage \\
\hline \multicolumn{7}{|l|}{ Test 1} \\
\hline CODsol (mg/L) & $56 \pm 9$ & $210 \pm 25$ & $930 \pm 135$ & $520 \pm 79$ & $252 \pm 36$ & $871 \pm 99$ \\
\hline Proteins (mg/L) & $65 \pm 19$ & $258 \pm 52$ & $650 \pm 164$ & $279 \pm 59$ & $264 \pm 46$ & $664 \pm 117$ \\
\hline \multicolumn{7}{|l|}{ Test 2} \\
\hline CODsol (mg/L) & $134 \pm 26$ & $1,520 \pm 198$ & $2,180 \pm 247$ & $2,082 \pm 609$ & $2,892 \pm 308$ & $2,482 \pm 267$ \\
\hline Proteins $(\mathrm{mg} / \mathrm{L})$ & $89 \pm 21$ & $661 \pm 53$ & $1,388 \pm 198$ & $1,103 \pm 75$ & $818 \pm 130$ & $1,471 \pm 312$ \\
\hline
\end{tabular}




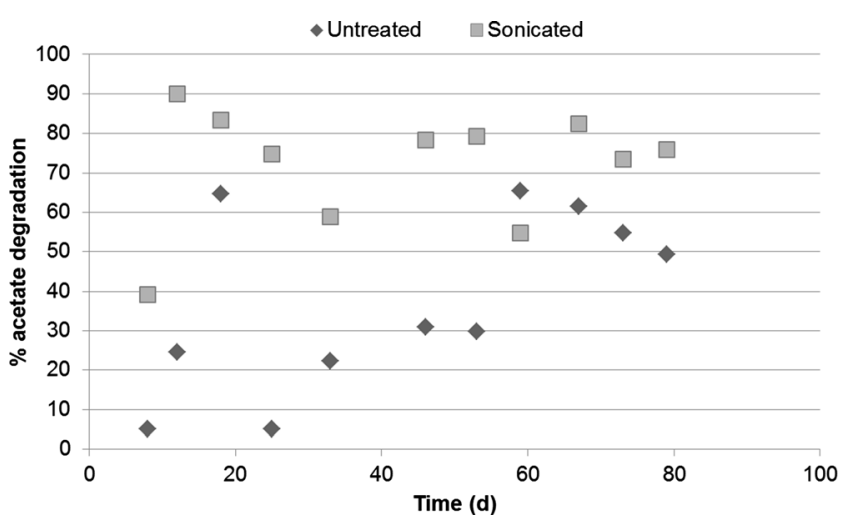

Fig. 7 Acetate degradation in thermophilic stage during test 2 in reactor fed with untreated and sonicated sludge

soluble organics and convert them into end-products of fermentation. On the other hand, methanogens have a very complex metabolic system that comprises all of enzymes required for methane production, and they modulate this machinery in relation to substrate availability. Moreover, they have different growth kinetics with respect to bacteria. For example, the hydrogenotrophic methanogen Methanothermobacter thermoautotrophicus, did not grow when a very low $\mathrm{H}_{2}$ was supplied, although methanogenesis continued and transcription of genes for methanogenesis was stimulated (Morgan et al. 1997); in this manner, it can optimize $\mathrm{H}_{2}$ utilization obtaining high yield of methane in $\mathrm{H}_{2}$-limiting environments, without exponential growth. This means that the abundance or the number of components of Methanothermobacter population is not directly related to methane yield.

Under mesophilic conditions, acetotrophic methanogenesis is the main way of acetate production. Only the genera Methanosarcina and Methanosaeta are able to transform acetate into methane (Smith and Ingram-Smith 2007). Their growth kinetics are mainly related to acetate and proportional to its concentration. In low acetate environments, Methanosaeta prevails on Methanosarcina because of its higher affinity for the substrate (Berger et al. 2012), and vice versa. Nevertheless, their simultaneous presence can benefit the process due to the higher metabolic versatility of Methanosarcina, as it can use almost all substrates for

Table 3 Shannon-Weaver $\left(H^{\prime}\right)$ and evenness $(E)$ values calculated for the two digestion tests in dual-stage system at the end of each digestion period

\begin{tabular}{|c|c|c|c|c|c|c|c|c|}
\hline & \multicolumn{4}{|c|}{ Mesophilic stage } & \multicolumn{4}{|c|}{ Thermophilic stage } \\
\hline & \multicolumn{2}{|c|}{ Untreated } & \multicolumn{2}{|c|}{ Sonicated } & \multicolumn{2}{|c|}{ Untreated } & \multicolumn{2}{|c|}{ Sonicated } \\
\hline & Test 1 & Test 2 & Test 1 & Test 2 & Test 1 & Test 2 & Test 1 & Test 2 \\
\hline$H^{\prime}$ & 1.4 & 1.3 & 1.4 & 1.4 & 0.5 & 0.7 & 0.6 & 0.5 \\
\hline$E$ & 0.7 & 0.7 & 0.70 & 0.7 & 0.7 & 0.5 & 0.8 & 0.7 \\
\hline
\end{tabular}

methanogenesis, with the exception of formate (Braguglia et al. 2012). Methanosarcina and Methanosaeta were found also in thermophilic processes, but their activity is often limited because of acetate utilization is mostly exploited by fermentative bacteria during SAO. Indeed, the syntrophs of acetate oxidizing bacteria and their partner hydrogenotrophic methanogens are able to successfully outcompete the aceticlastic methanogens (Hao et al. 2011). In thermophilic conditions, in the absence of acetotrophic methanogens, microbial communities could still maintain a highly efficient and stable performance without acetate accumulation (Krakat et al. 2010). For this reason, acetate was converted via $\mathrm{SAO}$, and the high hydrogenotrophic activity retrieved in several biogas reactors using acetate as carbon source supported this opinion (Hao et al. 2011). In this study, FISH analysis highlighted the presence of aceticlastic methanogens during the mesophilic stage, while Methanothermobacter population was the only species identified during thermophilic stage. As acetate was the main substrate during thermophilic stage in test 2, the original syntrophic association between Methanothermobacter and Coprothermobacter was replaced by a different hydrogenotrophic pathway, likely related to SAO.

\section{Conclusions}

Study of microbial populations during the innovative dualstage mesophilic/thermophilic AD indicated HRT of the mesophilic stage as crucial parameter to improve the performance of the following thermophilic stage. Shortening the HRT, a shift from methane to VFA production was observed, in particular by pretreating the sludge with ultrasounds. In thermophilic stage, substrate composition and availability strongly influenced the composition of the microbial population. In particular, the proteolytic Coprothemobacter deriving from thermophilic inoculum drastically decreased, and other bacteria, likely involved in syntrophic acetate oxidation, took place. Species richness was lower under thermophilic conditions compared with the values estimated in mesophilic $\mathrm{AD}$ and it was flanked by similar trend of the evenness, indicating that thermophilic microbial communities may require a longer acclimation period before obtaining a stable microbial population being more susceptible to sudden changes and less prompt to adapting to operative variations.

Acknowledgments This work was supported by ROUTES project. This project has received funding from the European Union's Seventh Programme for research, technological development, and demonstration under grant agreement no. 265156. The authors are grateful to Dr. Kohei Nakamura for providing pseudomurein endopeptidase and for the precious suggestions about FISH analysis. The authors thank Raffaele Cesarini and Renato Di Lorenzi for reactors operation and VFA analysis. 


\section{References}

Amani T, Nosrati M, Sreekrishnan TR (2010) Anaerobic digestion from the viewpoint of microbiological, chemical, and operational aspects-a review. Environ Rev 18:255-278. doi:10.1139/A10-011

Amann R, Binder B (1990) Combination of 16S rRNA-targeted oligonucleotide probes with flow cytometry for analyzing mixed microbial populations. Appl Environ Microbiol 56:1919-1925

APHA (1998) APHA standard methods for the examination of water and wastewater, 20th edn. American Public Health Association, Washington, DC

Ariesyady HD, Ito T, Okabe S (2007) Functional bacterial and archaeal community structures of major trophic groups in a full-scale anaerobic sludge digester. Water Res 41:1554-1568. doi:10.1016/j. watres.2006.12.036

Berger S, Welte C, Deppenmeier U (2012) Acetate activation in Methanosaeta thermophila: characterization of the key enzymes pyrophosphatase and acetyl-CoA synthetase. Archaea 2012: 315153. doi: $10.1155 / 2012 / 315153$

Bougrier C, Carrère H, Delgenès JP (2005) Solubilisation of wasteactivated sludge by ultrasonic treatment. Chem Eng J 106:163169. doi:10.1016/j.cej.2004.11.013

Bougrier C, Albasi C, Delgenès JP, Carrère H (2006) Effect of ultrasonic, thermal and ozone pre-treatments on waste activated sludge solubilisation and anaerobic biodegradability. Chem Eng Process 45:711-718. doi:10.1016/j.cep.2006.02.005

Braguglia CM, Gagliano MC, Rossetti S (2012) High frequency ultrasound pretreatment for sludge anaerobic digestion: effect on floc structure and microbial population. Bioresour Technol 110:43-49. doi:10.1016/j.biortech.2012.01.074

Carlsson M, Lagerkvist A, Morgan-Sagastume F (2012) The effects of substrate pre-treatment on anaerobic digestion systems: a review. Waste Manag 32:1634-1650. doi:10.1016/j.wasman.2012.04.016

Carrère H, Dumas C, Battimelli A et al (2010) Pretreatment methods to improve sludge anaerobic degradability: a review. J Hazard Mater 183:1-15. doi:10.1016/j.jhazmat.2010.06.129

Coelho NMG, Droste RL, Kennedy KJ (2011) Evaluation of continuous mesophilic, thermophilic and temperature phased anaerobic digestion of microwaved activated sludge. Water Res 45:2822-2834. doi: 10.1016/j.watres.2011.02.032

Etchebehere C, Pavan ME, Zorzópulos J et al (1998) Coprothermobacter platensis sp. nov., a new anaerobic proteolytic thermophilic bacterium isolated from an anaerobic mesophilic sludge. Int J Syst Bacteriol 48(Pt 4):1297-1304

Ge H, Jensen PD, Batstone DJ (2010) Pre-treatment mechanisms during thermophilic-mesophilic temperature phased anaerobic digestion of primary sludge. Water Res 44:123-130. doi:10.1016/j.watres.2009. 09.005

Ge H, Batstone DJ, Jensen PD (2012) Effect of temperature increase from $55{ }^{\circ} \mathrm{C}$ to $70{ }^{\circ} \mathrm{C}$ on anaerobic digestion: methanogenic activity and microbial community. In: Bianca Di Salvo, AWA Biosolids and Source Management National Conference: Program and Abstracts. AWA Biosolids and Source Management National Conference, Gold Coast, Qld., Australia (51-51). 18-20 June 2012. http:// espace.library.uq.edu.au/view/UQ:278537

Gianico A, Braguglia CM, Cesarini R, Mininni G (2013) Reduced temperature hydrolysis at $134{ }^{\circ} \mathrm{C}$ before thermophilic anaerobic digestion of waste activated sludge at increasing organic load. Bioresour Technol 143:96-103. doi:10.1016/j.biortech.2013.05.069

Gianico A, Braguglia CM, Gallipoli A, Mininni G (2014) Sonication of waste activated sludge before two-stage mesophilic/thermophilic anaerobic semi-continuous process: performances and energy balance. Environ Sci Pollut Res (in press)

Hao L-P, Lü F, He P-J et al (2011) Predominant contribution of syntrophic acetate oxidation to thermophilic methane formation at high acetate concentrations. Environ Sci Technol 45:508-513. doi:10.1021/ es $102228 \mathrm{v}$

Heip C (1974) A new index measuring evenness. J Mar Biol Assoc UK 54:555-557

Ho DP, Jensen PD, Batstone DJ (2013) Methanosarcinaceae and acetateoxidizing pathways dominate in high-rate thermophilic anaerobic digestion of waste-activated sludge. Appl Environ Microbiol 79: 6491-6500. doi:10.1128/AEM.01730-13

Hori T, Haruta S, Ueno Y (2006) Dynamic transition of a methanogenic population in response to the concentration of volatile fatty acids in a thermophilic anaerobic digester. Appl Environ Microbiol 72:16231630. doi:10.1128/AEM.72.2.1623

Ike M, Inoue D, Miyano T et al (2010) Microbial population dynamics during startup of a full-scale anaerobic digester treating industrial food waste in Kyoto eco-energy project. Bioresour Technol 101: 3952-3957. doi:10.1016/j.biortech.2010.01.028

Karakashev D, Batstone DJ, Trably E, Angelidaki I (2006) Acetate oxidation is the dominant methanogenic pathway from acetate in the absence of Methanosaetaceae. Appl Environ Microbiol 72: 5138-5141. doi:10.1128/AEM.00489-06

Krakat N, Westphal A, Schmidt S, Scherer P (2010) Anaerobic digestion of renewable biomass: thermophilic temperature governs methanogen population dynamics. Appl Environ Microbiol 76: 1842-1850. doi:10.1128/AEM.02397-09

Lauwers J, Appels L, Thompson IP et al (2013) Mathematical modelling of anaerobic digestion of biomass and waste: Power and limitations. Prog Energy Combust Sci 39:383-402. doi:10.1016/j.pecs.2013.03. 003

Lee M, Hidaka T, Tsuno H (2009) Two-phased hyperthermophilic anaerobic co-digestion of waste activated sludge with kitchen garbage. $\mathrm{J}$ Biosci Bioeng 108:408-413. doi:10.1016/j.jbiosc.2009.05.011

Loy A, Maixner F, Wagner M, Horn M (2007) probeBase-an online resource for rRNA-targeted oligonucleotide probes: new features. Nucleic Acids Res 35:D800-D804. doi:10.1093/nar/gk1856

Lü F, Bize A, Guillot A et al (2014) Metaproteomics of cellulose methanisation under thermophilic conditions reveals a surprisingly high proteolytic activity. ISME J 8:88-102. doi:10.1038/ismej.2013. 120

Majeed T, Tabassum R, Orts WJ, Lee CC (2013) Expression and characterization of coprothermobacter proteolyticus alkaline serine protease. Sci World J 2013:1-6. doi:10.1155/2013/396156

Merlino G, Rizzi A, Schievano A et al (2013) Microbial community structure and dynamics in two-stage vs single-stage thermophilic anaerobic digestion of mixed swine slurry and market bio-waste. Water Res 47:1983-1995. doi:10.1016/j.watres.2013.01.007

Montero B, García-Morales JL, Sales D, Solera R (2009) Analysis of methanogenic activity in a thermophilic-dry anaerobic reactor: use of fluorescent in situ hybridization. Waste Manag 29:1144-1151. doi:10.1016/j.wasman.2008.08.010

Morgan R, Pihl T, Nölling J, Reeve JN (1997) Hydrogen regulation of growth, growth yields, and methane gene transcription in Methanobacterium thermoautotrophicum deltaH. J Bacteriol 179: 889-898

Nakamura K, Terada T, Sekiguchi Y et al (2006) Application of pseudomurein endoisopeptidase to fluorescence in situ hybridization of methanogens within the family Methanobacteriaceae. Appl Environ Microbiol 72:6907-6913. doi:10.1128/AEM.01499-06

Nelson MC, Morrison M, Yu Z (2011) A meta-analysis of the microbial diversity observed in anaerobic digesters. Bioresour Technol 102: 3730-3739. doi:10.1016/j.biortech.2010.11.119

O'Flaherty V, Collins G, Mahony T (2006) The microbiology and biochemistry of anaerobic bioreactors with relevance to domestic sewage treatment. Rev Environ Sci Biotechnol 5:39-55. doi:10.1007/ s11157-005-5478-8

Ollivier BM, Mah RA, Ferguson TJ et al (1985) Emendation of the genus Thermobacteroides: Thermobacteroides proteolyticus sp. nov., a 
proteolytic acetogen from a methanogenic enrichment. Int J Syst Bacteriol 35:425-428. doi:10.1099/00207713-35-4-425

Paul E, Carrère H, Batstone DJ (2012) In: Paul E, Liu Y (eds) Biological sludge minimization and biomaterials/bioenergy recovery technologies. John Wiley \& Sons, Inc., New Jersey, pp 373-404

Pavlostathis S, Giraldo-Gomez E (1991) Kinetics of anaerobic treatment. Water Sci Technol 24:35-59

Pervin HM, Batstone DJ, Bond PL (2013a) Previously unclassified bacteria dominate during thermophilic and mesophilic anaerobic pre-treatment of primary sludge. Syst Appl Microbiol 36:281-290. doi:10.1016/j.syapm.2013.03.003

Pervin HM, Dennis PG, Lim HJ et al (2013b) Drivers of microbial community composition in mesophilic and thermophilic temperature-phased anaerobic digestion pre-treatment reactors. Water Res 47:7098-7108. doi:10.1016/j.watres.2013.07.053

Sasaki K, Morita M, Sasaki D et al (2011) Syntrophic degradation of proteinaceous materials by the thermophilic strains Coprothermobacter proteolyticus and Methanothermobacter thermautotrophicus. J Biosci Bioeng 112:469-472. doi:10. 1016/j.jbiosc.2011.07.003

Shannon CE, Weaver W (1963) The mathematical theory of communication. University of Illinois Press, Urbana
Shi J, Wang Z, Stiverson JA et al (2013) Reactor performance and microbial community dynamics during solid-state anaerobic digestion of corn stover at mesophilic and thermophilic conditions. Bioresour Technol 136:574-581. doi:10.1016/j.biortech. 2013.02.073

Smith KS, Ingram-Smith C (2007) Methanosaeta, the forgotten methanogen? Trends Microbiol 15:150-155. doi:10.1016/j.tim. 2007.02.002

Sundberg C, Al-Soud WA, Larsson M et al (2013) 454 Pyrosequencing analyses of bacterial and archaeal richness in 21 full-scale biogas digesters. FEMS Microbiol Ecol 85:612-626. doi:10.1111/15746941.12148

Tandishabo K, Nakamura K, Umetsu K, Takamizawa K(2012) Distribution and role of Coprothermobacter spp. in anaerobic digesters. J Biosci Bioeng 114:518-520. doi:10.1016/j.jbiosc.2012.05.023

Wilén B-M, Onuki M, Hermansson M et al (2008) Microbial community structure in activated sludge floc analysed by fluorescence in situ hybridization and its relation to floc stability. Water Res 42:2300 2308. doi:10.1016/j.watres.2007.12.013

Zamanzadeh M, Parker WJ, Verastegui Y, Neufeld JD (2013) Biokinetics and bacterial communities of propionate oxidizing bacteria in phased anaerobic sludge digestion systems. Water Res 47:15581569. doi:10.1016/j.watres.2012.12.015 